\title{
A new paradigm in the management of acute type $A$ aortic dissection: Total aortic repair
}

\author{
George Matalanis, BSc, MB, MS, FRACS, and Shoane Ip, MBBS, BMedSc, FRACS
}

\begin{abstract}
The currently accepted guidelines of open surgical repair for acute type A aortic dissection include the resection of the primary entry tear, replacement of the ascending aorta and "hemi-arch" with an open distal anastomosis, and aortic valve resuspension and some form of obliteration of the aortic root false lumen. The principal aim is protection against aortic rupture, aortic regurgitation, and coronary ischemia and restoration of antegrade preferential true lumen perfusion. Proponents argue that this operation is tailored to be in the armamentarium of most cardiac surgeons and deliver the lowest early operative risk while leaving the infrequent long-term sequelae to be dealt with electively by experienced aortic centers. Although this may sound to be a compelling argument, the actual outcomes suggest that it falls significantly short of achieving its noble goals on both acute and chronic counts. This led us to develop a seemingly more radical paradigm, which aims to achieve total aortic healing in the acute phase. We describe a total aortic repair technique for acute type A aortic dissection consisting of "branch first" total arch repair, followed by thoracoabdominal stenting and balloon rupture of the septum. The total aortic repair technique ensures that the aortic valve, ascending aorta, and arch are surgically securely repaired, and provides complete decompression of the false lumen as well as internal support in the remainder of the aorta. This has provided excellent early results and will hopefully minimize future complications and interventions. (J Thorac Cardiovasc Surg 2019;157:3-11)
\end{abstract}

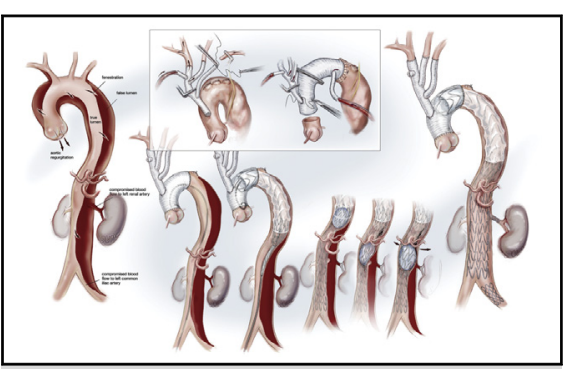

Total aortic repair: "branch first" total arch replacement and thoracoabdominal stenting.

\section{Central Message}

We describe a total aortic repair technique for acute type A aortic dissection consisting of "branch-first" total arch repair, followed by thoracoabdominal stenting and balloon rupture of the septum.

\section{Perspective}

Current treatment for acute type A aortic dissection is still associated with significant early and interval complications. The total aortic repair technique ensures that the aortic valve, ascending aorta, and arch are surgically securely repaired and provides complete decompression of the false lumen as well as internal suppor in the remainder of the aorta. This has provided excellen early results and will hopefully minimize future complications and interventions.

See Editorial Commentary page 12 .

See Editorial page 1.
Management of acute type A aortic dissection (ATAAD) by the "hemi-arch" technique with open distal anastomosis is currently favored because it is believed to carry a lower operative risk than more aggressive resections while not requiring excessive need for later interventions on the downstream aorta. It has been further argued that should future complications occur, they can be managed in experienced aortic centers with acceptably low morbidity and mortality. Although it is difficult to argue against such noble intentions, we need to ask for the evidence. May a seemingly more extensive procedure that more completely and reliably corrects the underlying pathology yield better outcomes both in the early phase as well as the longer term?

From the Department of Cardiac Surgery, Austin Hospital, Heidelberg, Australia. Read at The American Association for Thoracic Surgery Aortic Symposium 2018, New York, New York, April 26-27, 2018.

Received for publication May 26, 2018; revisions received Aug 6, 2018; accepted for publication Aug 24, 2018.

Address for reprints: George Matalanis, BSc, MB, MS, FRACS, Department of Cardiothoracic Surgery, The Austin Hospital, PO Box 555, Heidelberg, Victoria 3084, Australia (E-mail: george.matalanis@austin.org.au). $0022-5223 / \$ 36.00$

Crown Copyright $(\subset) 2018$ Published by Elsevier Inc. on behalf of The American Association for Thoracic Surgery

https://doi.org/10.1016/j.jtcvs.2018.08.118

Scanning this $\mathrm{QR}$ code will take you to the article title page to access supplementary information. To view the Webcast, see the URL next to the webcast thumbnail. 


\section{Abbreviations and Acronyms}

ATAAD $=$ acute type $\mathrm{A}$ aortic dissection

$\mathrm{FL} \quad=$ false lumen

TAR $=$ total arch replacement

$\mathrm{TL} \quad=$ true lumen

\section{CONSERVATIVE RESECTION OUTCOMES \\ Acute Results}

Despite modern developments, the mortality of ATAAD has remained at $17 \%$ to $26 \%$ in the International Registry of Acute Aortic Dissections registry ${ }^{1}$ over the last decade or so. It might be argued that acute salvage is strongly influenced by the presence and extent of preoperative complications such as shock and organ mal-perfusion. ${ }^{2}$ Nevertheless, in a recent series, ${ }^{3}$ the mortality was still $14 \%$ in the most frequent $(61 \%)$ and lowest risk subgroup, where outcomes would be expected to approach an elective operation.

An important but frequently neglected factor in postprocedural complications is the persistence of false lumen (FL) pressurization. Reasons include failure to resect either the primary or large re-entry tears in the upper descending aorta or persistent communications at the suture lines. In the aortic root, this can result in severe aortic regurgitation and coronary ischemia, whereas distally it may result in persistent/recurrent organ or limb mal-perfusion. Finally, in either direction, it can lead to disruption of fresh suture lines with uncontrollable bleeding.

\section{Medium- and Long-Term Outcomes}

Superficially, the outcomes seem acceptable, with 5- and 10 -year survival of $70 \%$ to $80 \%$ and $50 \%$ to $65 \%$, respectively, and a distal reoperation rate of $5 \%$ to $15 \%$ and $15 \%$ to $25 \%$ at 5 and 10 years. ${ }^{4-6}$ However, a more careful analysis reveals a very different picture. First, dissections confined to the ascending with or without the arch ("extended" DeBakey Type II) represent approximately $35 \%$ of all ATAAD and unsurprisingly have a much better outlook, with 5-year survival and freedom from distal reintervention of $80 \%$ and $100 \%$, respectively, versus $63 \%$ and $53 \%$ in those with Type I ATAAD. ${ }^{7}$ Second, the persistence of FL patency portends worse 10-year survival $(60 \%$ vs $90 \%)$ and freedom from distal reintervention $(64 \%$ vs $94 \%) .{ }^{8}$ Third, although reintervention can be performed with very good outcomes in selected aortic centers, ${ }^{9}$ it still

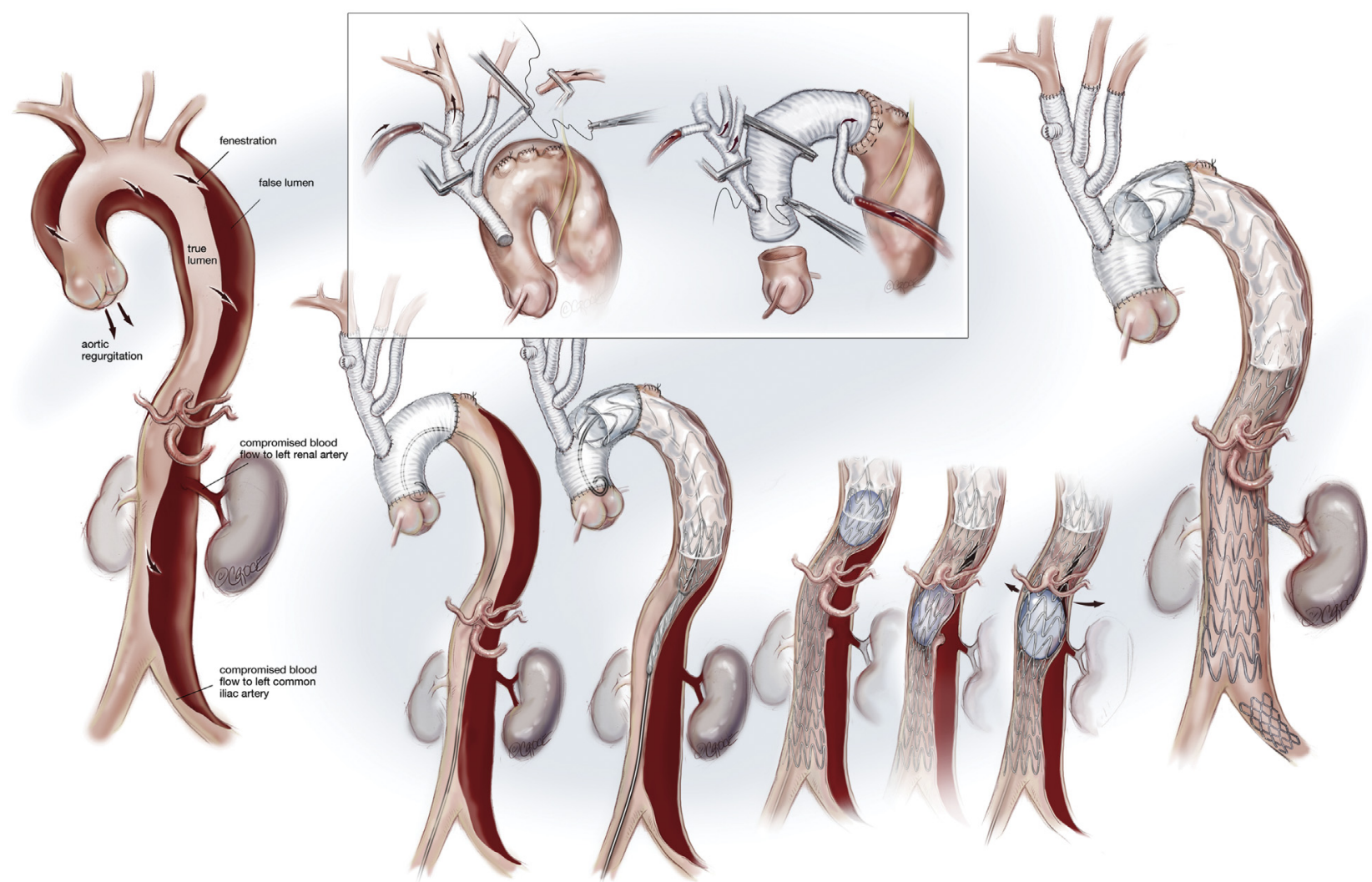

FIGURE 1. Total aortic repair for acute type A aortic dissection commences with total arch replacement using the branch-first technique. In suitable patients, the second stage is implemented. This consists of covered stent grafting of the upper two-thirds of the descending aorta and uncovered stent grafting of the remaining thoraco-abdominal aorta. A complete septal fenestration using an angioplasty balloon is performed, from the junction of the covered and uncovered stent grafts, down to the aortic bifurcation. Visceral or iliac branch realignment is performed with covered stent grafts when required. 
carries significant complications compared with equivalent first-time aortic surgery in those institutions, let alone in the hands of the average surgeon. Even total endovascular reinterventions carry significant risks of not only mortality but stroke and paraplegia and are plagued by endoleaks. ${ }^{10}$ Finally, many aortic ruptures occurred in patients under close and regular surveillance, ${ }^{5}$ let alone those lost to follow-up.

\section{THE DRIVING FORCE FOR FL GROWTH}

A weakened wall consisting of fewer layers and La Place's law acting on a larger total external diameter of aorta are often cited causes of FL growth. However, more importantly is the development of chronic FL diastolic hypertension. This occurs when there are large proximal descending aortic re-entry tears and small distal re-entry tears. Thus, blood enters the FL freely during systole but drains poorly in diastole through the serpiginous and small distal tears, when compared with the rapid distal run off in the true lumen (TL). ${ }^{11}$ This explains the seemingly paradoxical situation in which partial thrombosis of the FL has a worse outcome than a completely patent one. ${ }^{12}$ Added to this is the high shear forces from turbulence in the FL near the proximal entry site. ${ }^{13}$
A

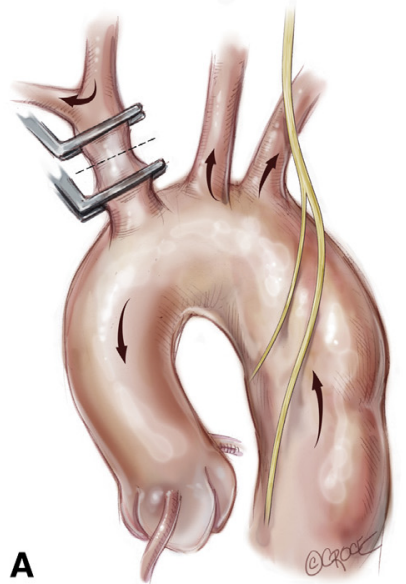

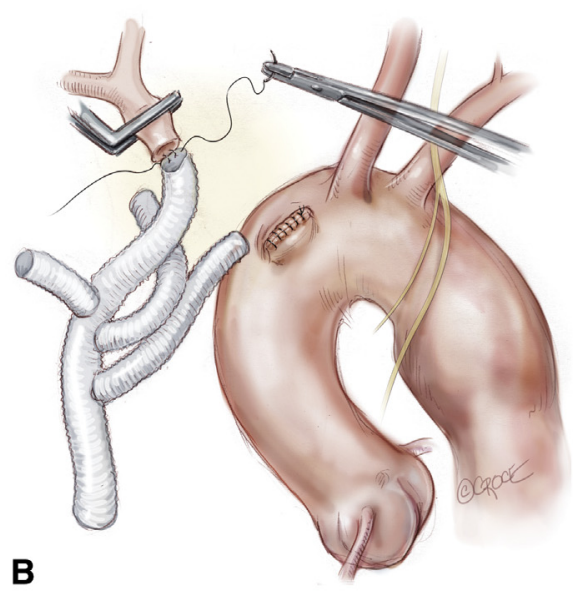

C
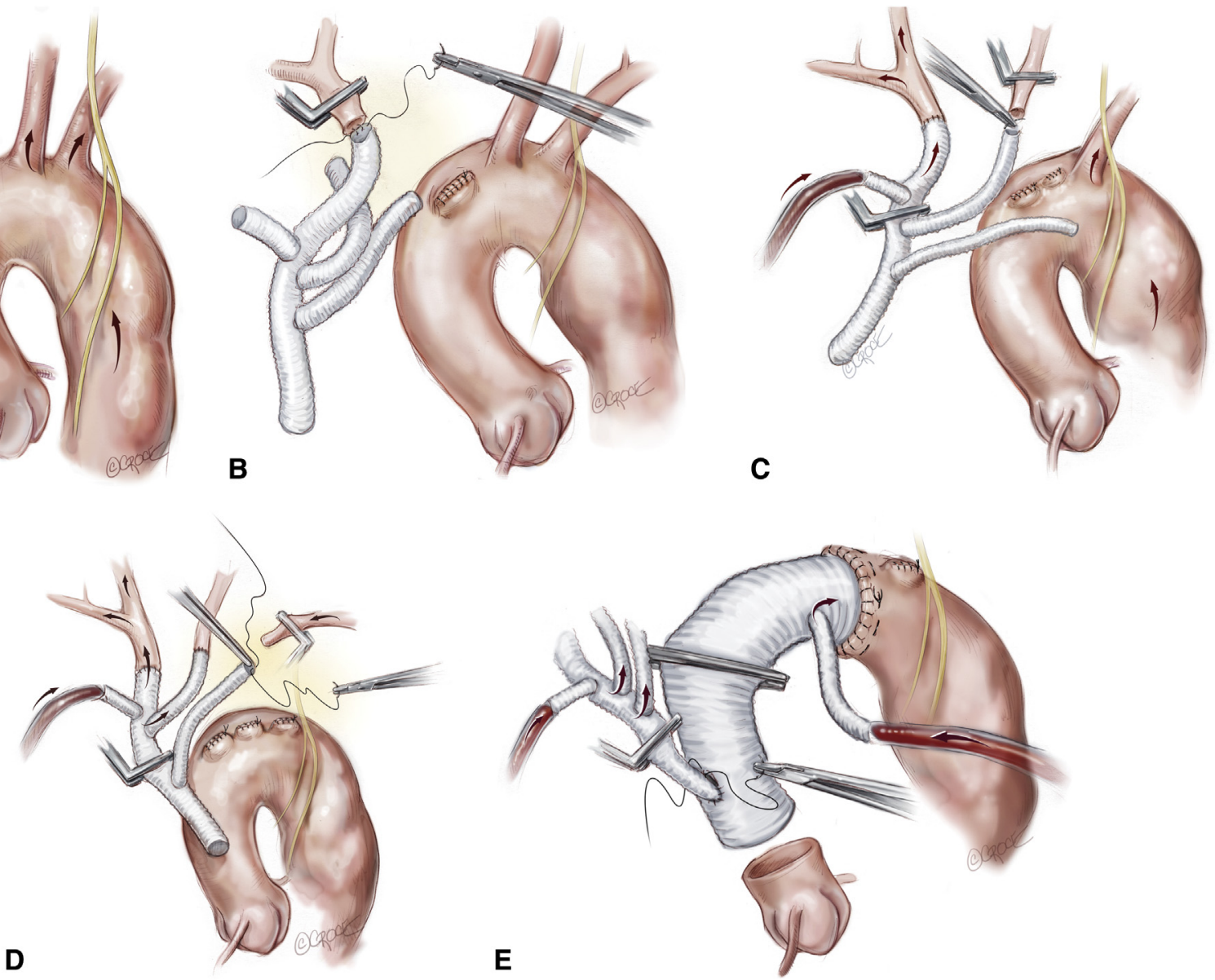

FIGURE 2. After the establishment of cardiopulmonary bypass, the "branch-first" aortic arch reconstruction proceeds as follows: A, the innominate artery is clamped proximal to its bifurcation and distal to its origin from the arch. Right hemispheric cerebral perfusion is maintained through the left common carotid and subclavian arteries via collateral channels. Apart from the circle of Willis, there is a plethora of extracranial collateral channels that augment cerebral perfusion during individual clamping of branch vessels. These include collateral channels between the external and internal carotid arteries; the right and the left carotid arteries; the upper and lower body; and the subclavian and carotid arteries ${ }^{4}$; $\mathrm{B}$, the innominate stump is ligated and the anastomosis to the first limb of the branched graft completed; $\mathrm{C}$, antegrade right hemispheric cerebral perfusion is resumed via the perfusion side arm. Left hemispheric cerebral perfusion during construction of the left common carotid anastomosis is maintained via the same collaterals described previously; D, subclavian anastomosis is completed and all 3 arch branches are perfused; E, anastomosis of the arch graft to the distal arch. Note that the distal anastomoses can be performed in Zone 2, which is usually better-quality tissue, allows improved access to the anastomoses, and reduces the risk of recurrent laryngeal nerve injury. Antegrade flow is recommenced via the "ante flow" side arm of the graft. After completion of the root anastomosis, connection of the trifurcation arch graft with side perfusion port (TAPP graft) to the ascending graft proceeds without interruption of cerebral perfusion. Copyright Beth Croce, Bioperspective.com. 

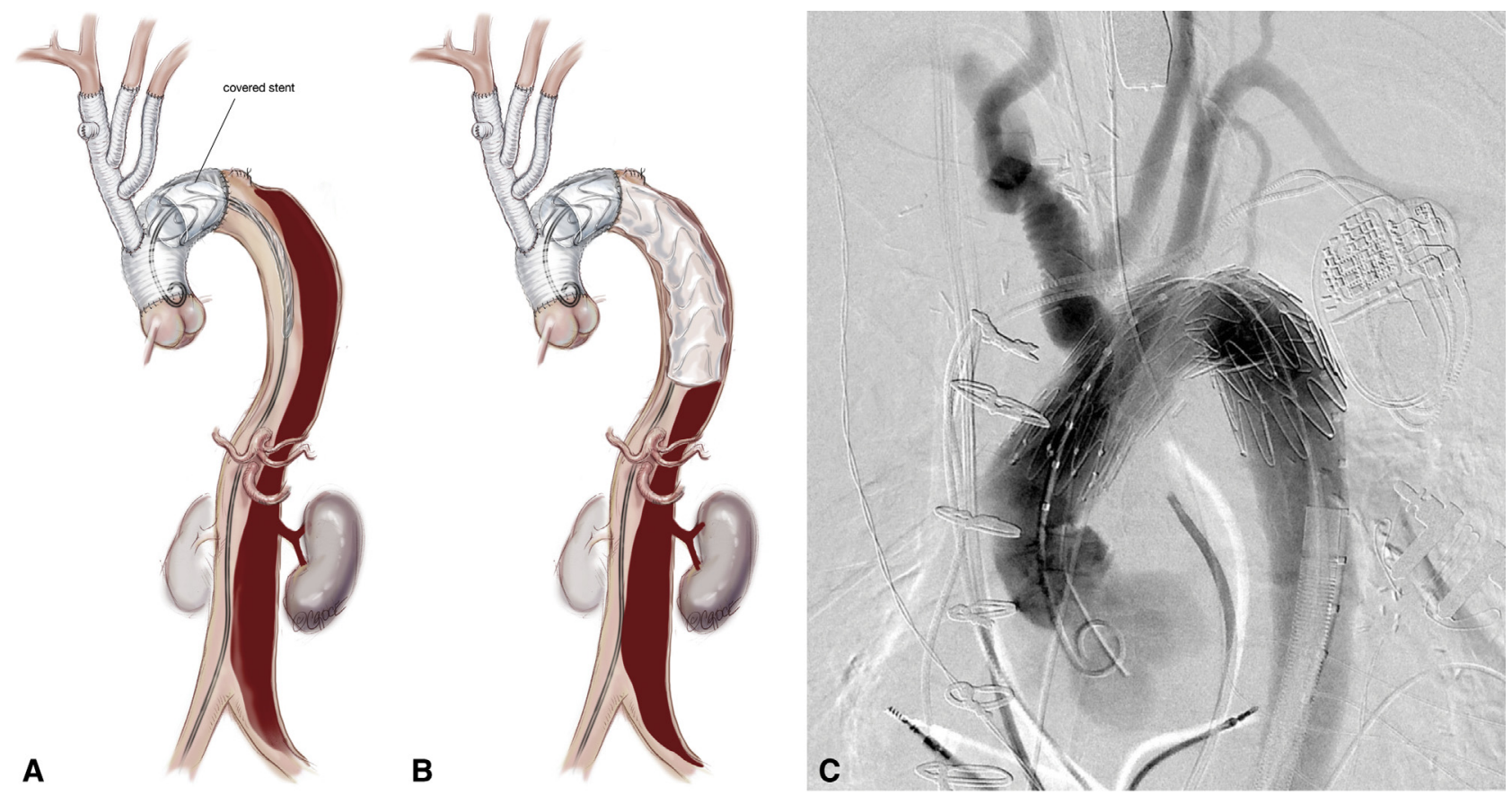

FIGURE 3. A, A covered stent graft (Zenith TX2 TAA 112 Endovascular Graft, Cook Medical Inc, Bloomington, Ind) is introduced and positioned within the predesigned Dacron proximal landing zone. B, The first stent is deployed so that the distal end is positioned at the junction of middle and upper third of the descending thoracic aorta. Further covered stent grafts can be deployed down to the diaphragm/celiac trunk if required but increased coverage is associated with increased risk of spinal cord injury. C, Digital subtraction angiography demonstrating the covered stent extending from the Dacron landing zone into the upper descending aorta. Copyright Beth Croce, Bioperspective.com.

\section{HOW CAN WE IMPROVE THE EARLY AND LATE RESULTS?}

Understanding the underlying mechanisms, there are 2 potential modes of attack, outlined in the sections to follow.

\section{Obliterate Large Proximal Entry Sites \\ Total arch replacement (TAR). Performing a routine TAR in ATAAD has the potential to remove more intimal tears apart from the primary tear. It may also capture more of the very proximal descending tears. This has been reasonably criticized as possibly carrying a greater early complication rate in the acute setting. A recent large meta-analysis has not shown an increase in mortality with TAR. ${ }^{14}$ Unfortunately, there also was no significant reduction in long-term distal aortic events. This is not surprising, given that the extra aorta removed in TAR compared with hemi-arch is minor. Nonetheless, TAR combined with appropriate management of the root minimizes the need for a difficult resternotomy to treat residual disease in the proximal aorta and arch. Second, providing a long Dacron (Invista, Wichita, Kan) "landing zone" away from the arch branches greatly increases the facility and options of future endovascular treatment.}

TAR and "Frozen Elephant Trunk." Extending the length of descending aorta whose intimal tears are sealed with stents achieves approximately $90 \%$ thrombosis and shrinkage of the FL in the segment of aorta treated. ${ }^{15}$ Disappointingly, few obtained positive remodeling in the lower thoracic and abdominal aorta. Furthermore, there was a $7.5 \%$ incidence of paraplegia,${ }^{16}$ a hitherto rare complication of ATAAD repair. This was more likely with prolonged periods of circulatory arrest at greater temperatures and in the absence of antegrade cerebral perfusion, and with elephant trunks extending beyond T9. Vitally, if future procedures are required on the distal thoracoabdominal aorta, the complexity and risks are still significant.

\section{Distal Fenestration}

Localized. The percutaneous creation of a more generous re-entry was first described in $1990 .{ }^{17}$ This can be quite effective in relieving TL collapse in the vicinity of an ischemic visceral artery but is generally not sufficient to ensure complete decompression of the FL.

Extensive. A more extensive fenestration can be done surgically and provides good long-term outcomes. ${ }^{18}$ Nonetheless, the open procedure is a significantly invasive procedure. A percutaneous "cheese wire" technique for creating a long fenestration has been described ${ }^{19}$ but is technically challenging and has had limited application. A more facile technique involves the initial placement of bare metal stents in the lower thoracic and whole of the abdominal TL, which are then balloon expanded to produce a longitudinal and complete fenestration. ${ }^{20}$ 
Techniques to obliterate FL flow and pressurization have previously been described. The placement of bare metal stents to extend the thoracic endovascular graft through the dissected abdominal aorta in type B dissection (The "PETTICOAT" technique) was first described by Nienaber and colleagues in $2006 .{ }^{21}$ Although this proved to be successful in the treatment of cases of collapsed TL or malperfusion, which occurred despite endovascular coverage of entry tears in the thoracic aorta, it did not change the pressurized state of the FL. Thus, the concept was further developed by the "STABILISE" technique, in which a balloon was used to disrupt and fenestrate the intimal flap, to depressurize the FL, and achieve thrombosis and aortic healing. ${ }^{20}$ Although this technique was used to treat 7 patients after ATAAD, only 1 patient underwent TAR, and 2 patients required further intervention to treat endoleaks due to an inadequate proximal seal in the native arch. By contrast, our routine use of TAR in ATAAD provides a proximal Dacron landing zone for endovascular stenting, alleviating the problems that occur with landing the stent in native dissected aorta.

\section{THE PARADIGM SHIFT: TOTAL AORTIC REPAIR FOR ATAAD}

Using the preceding deliberations, we have arrived at a novel formulation for the management of ATAAD, with the desire of combining a safe acute operation together with the potential for achieving long-term healing of the entire aorta, with minimal future complications or need for reintervention (Figure 1).

\section{Stage 1}

The majority of patients presenting with ATAAD will proceed to a "branch first" total aortic arch repair as previously described by us. ${ }^{22}$ Essentially, this consists of sequential short period clamping and reperfusion of the 3 arch branches without circulatory arrest and using a modified trifurcation graft with a side perfusion port (Figure 2).

The distal anastomosis is performed using a short period of distal circulatory arrest with open distal anastomosis. It is essential to construct the proximal trifurcation to main Dacron graft anastomosis sufficiently proximally to allow a long "landing zone" for subsequent endovascular stenting.

We don't routinely use the frozen elephant trunk technique unless we have concern about the proximal descending aorta being very fragile, or containing a primary tear with retrograde ATAAD, or a large re-entry tear with preoperative distal mal-perfusion. Liberal use is made of valve-sparing root replacement or Bentall's procedure when appropriate.

\section{Stage 2}

The decision to proceed to stenting of the remaining dissected thoracoabdominal aorta is dependent on clinical and imaging grounds. In the uncommon situation
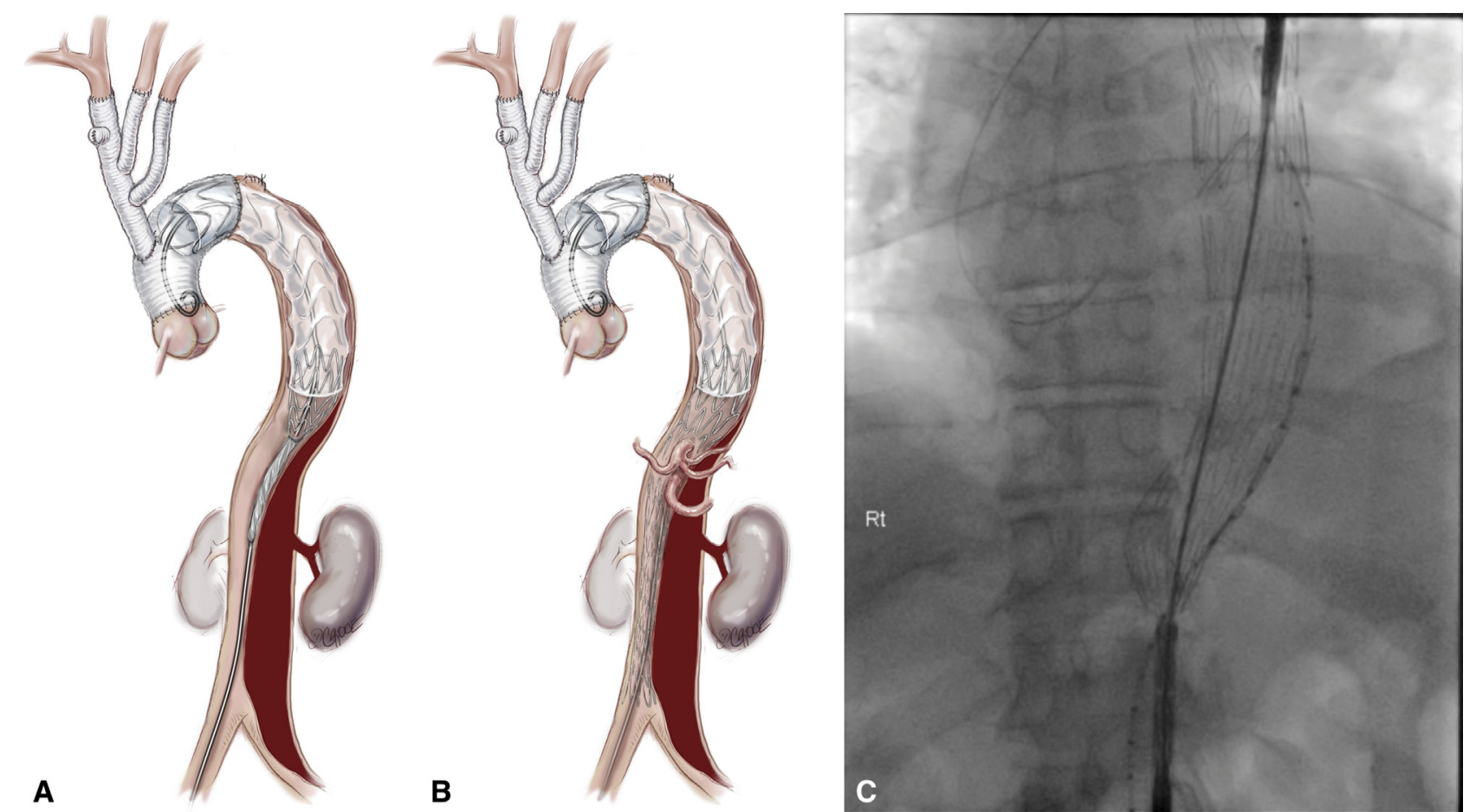

FIGURE 4. The remaining thoracic (A) and abdominal (B) aorta down to the aortic bifurcation is then lined with bare metal uncovered stent grafts (Zenith Dissection Endovascular Stent, Cook Medical Inc). C, Deployment of the uncovered stent graft with small overlap of previous stent. Copyright Beth Croce, Bioperspective.com. 
of a patient presenting with advanced visceral ischemia, stenting is performed preoperatively, allowing time for metabolic derangements to be corrected before ATAAD repair. Stenting has also been undertaken immediately after the completion of ATAAD repair in a few cases, for persistent malperfusion despite redirection of flow to the TL proximally. The majority have undergone the second stage either after discharge from ICU or on an early readmission. The indications for these included evolving malperfusion, a rapidly enlarging FL on CTA, or collapsed TL.

In the angiography suite, a covered endovascular stent is placed with a generous overlap proximally to the surgically created landing zone and extending distally to the level of mid descending aorta (Figure 3).

Uncovered dissection stents are then deployed through the remaining thoracoabdominal aorta to the bifurcation (Figure 4). The stents are then balloon dilated to rupture the septum between TL and FLs, beginning at the overlap between covered and uncovered stents and proceeding distally (Figure 5). Successful rupture of the septum is indicated by a "popping" sensation on the end of the syringe and a sudden enlargement of the TL, which doesn't recoil back after balloon deflation (Video 1). This serves the purpose of creating a single aortic channel, expanding the TL completely, and decompressing the FL to oppose the layers of the aorta, allowing healing of the layers and aortic remodeling. It is important not to inflate the balloon to a diameter greater than the maximum aortic diameter, as this may lead to aortic rupture.

If there is compromise to the visceral vessels that have some supply from the FL (particularly the renal arteries), it is pertinent to place a wire into these vessels before inflation to ensure timely access should perfusion be compromised with balloon inflation. In these cases, a covered visceral branch vessel stent can be deployed to re-establish flow to the compromised vessel (Figure 6).

Contraindications to bare metal stenting and balloon inflation include the presence of leak or suspicion of contained rupture with periaortic hematoma, or subacute dissection with large volume of FL thrombus leading to the risk of embolism. Finally, aortography is performed to confirm patency of the aorta and visceral vessels and obliteration of FL flow.

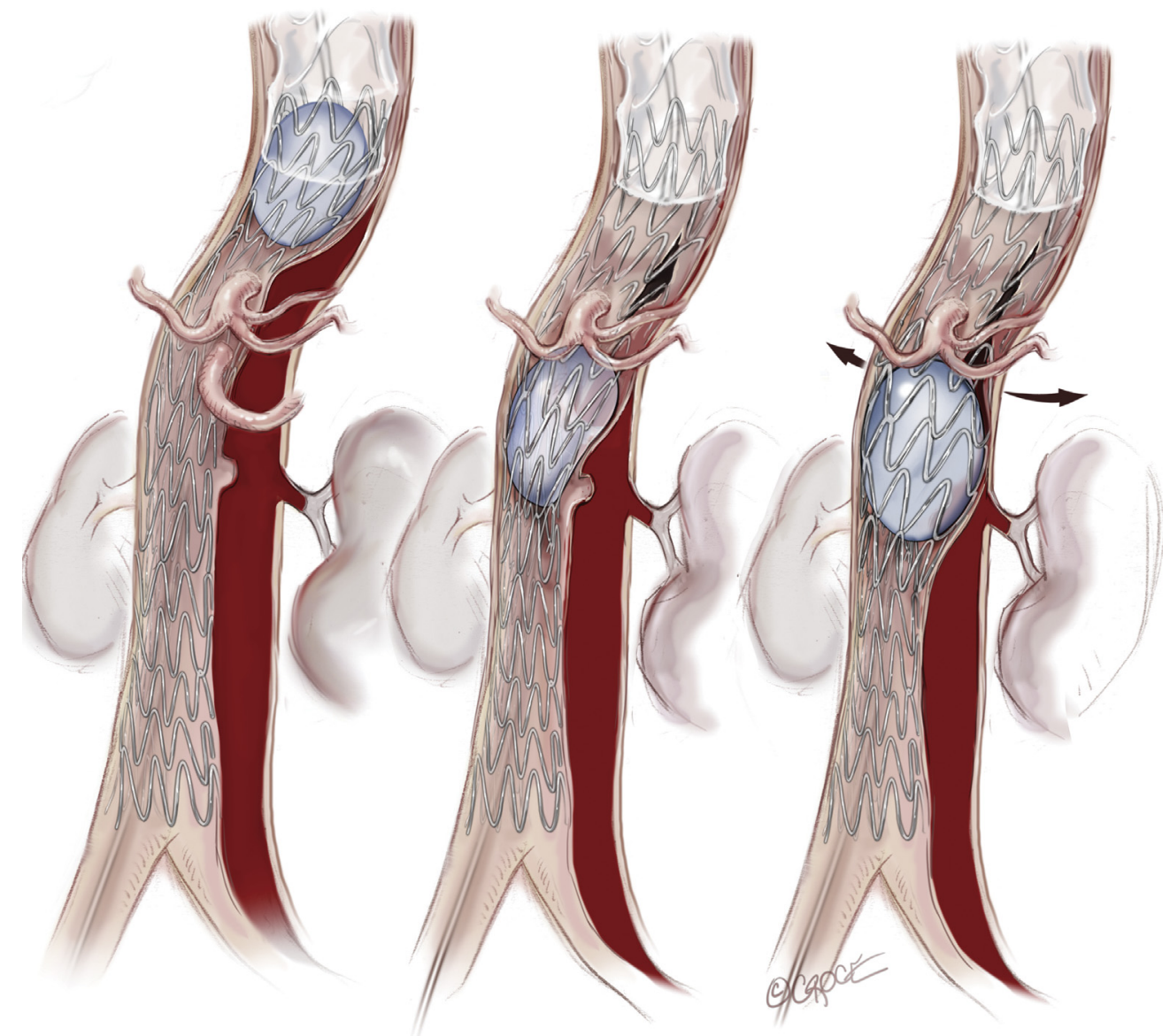

FIGURE 5. An angioplasty balloon (Coda Balloon Catheter, Cook Medical Inc) is then used to sequentially expand the bare metal stents and rupture the septum between the TL and FL to create a single aortic channel. Copyright Beth Croce, Bioperspective.com. 


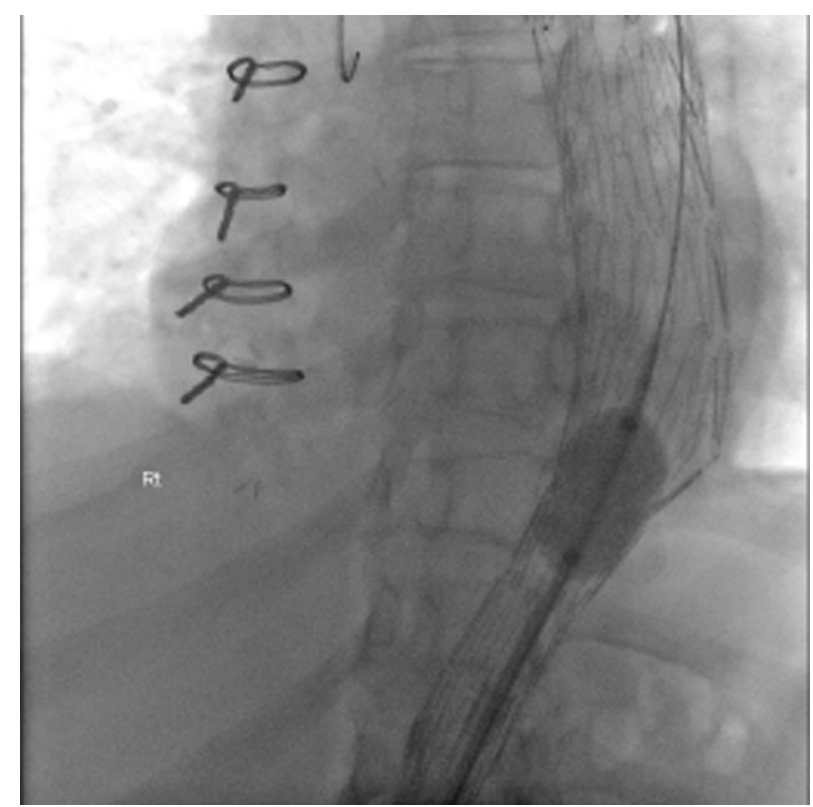

VIDEO 1. Balloon dilation of bare metal stent, showing rupture of septum. Video available at: https://www.jtcvs.org/article/S0022-5223(18) 32616-3/fulltext.

\section{EARLY EXPERIENCE}

Since 2012, there have been 72 presentations of ATAAD managed with surgical repair. Total aortic repair by the techniques described previously has been performed in 15 patients $(21 \%)$. Eleven patients $(73 \%)$ were male with a median age of 61 years (range, 19-74 years). Twelve of these patients $(80 \%)$ have undergone total aortic repair in the acute setting with thoracoabdominal stenting performed within 14 days of initial surgery. The interval from surgery until endovascular procedure in the 3 patients with chronic dissection ranged from 1022 to 2714 days. No patients in this series presented with preoperative malperfusion requiring endovascular treatment before surgical repair of ATAAD. Three patients underwent frozen elephant trunk as part of their primary ATAAD surgical repair. Indications for endovascular stenting were TL collapse in 10 patients, limb malperfusion in 2 patients, and expanding FL aneurysm in the proximal descending aorta in 2 patients. Balloon rupture of the septum was used in all patients.

Six patients required additional visceral stenting (1 right renal, 4 left renal, 1 left renal and superior mesenteric artery). Three patients required stenting into the common iliac arteries due to TL collapse.

There have been no intraprocedural complications relating to stent deployment, injury to vessels, or access complications. There have been no operative or 30-day mortalities. There has been one permanent neurologic event after stenting with minor residual deficit and no instances of paraplegia. Three patients required transient hemofiltration after total aortic repair in the acute setting.

Median length of follow-up since endovascular procedure has been 26 months (range 2-63 months), with computed tomography imaging available for a median of 21 months (1-60 months). There has been 1 non-aorticrelated death related to an aggressive recurrent brain tumor 4 months after endovascular stenting. There have been no late endovascular related adverse events.

FL thrombosis has been demonstrated in the covered stent region in all patients except one. This patient has a type 2 endoleak related to an intercostal artery supplying
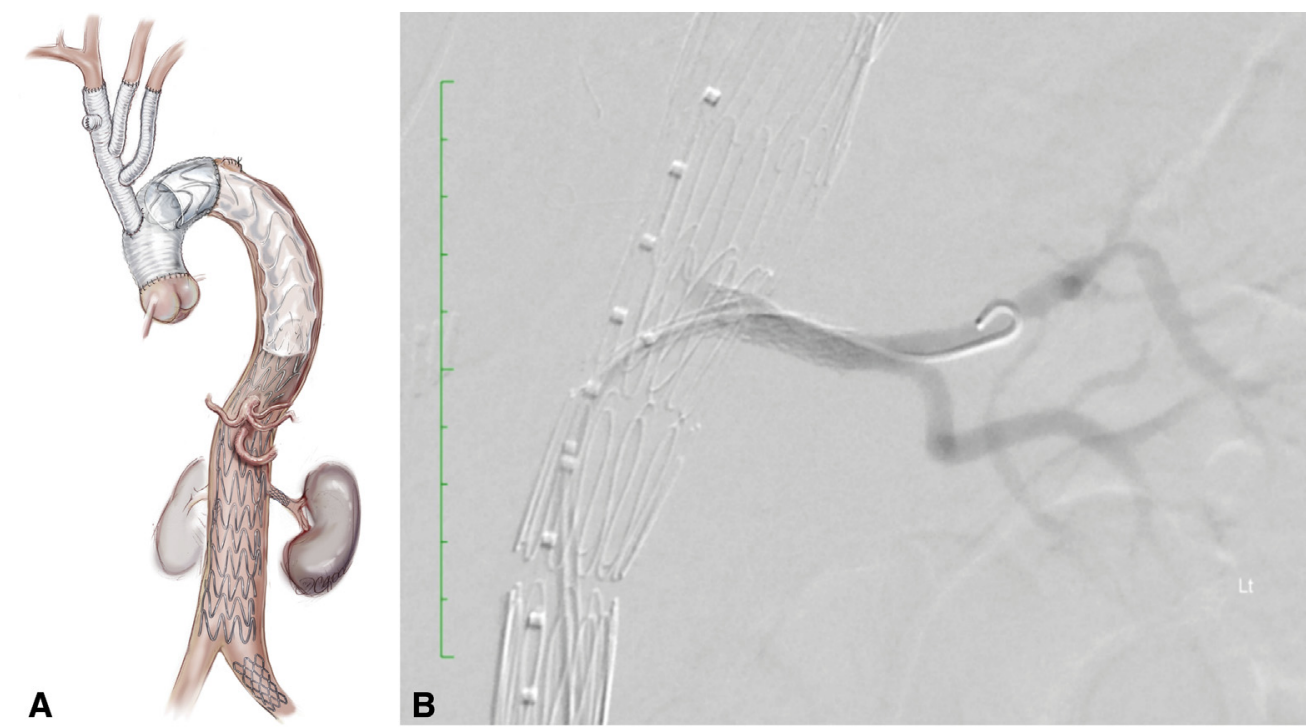

FIGURE 6. A, This patient also required stent grafting to the left renal artery and left common iliac artery. At the conclusion of the procedure, aortography is performed and the patency of the aortic lumen and the visceral and other branch vessels are confirmed. B, Digital subtraction angiography demonstrating restoration of flow to left renal artery after visceral branch stenting. Copyright Beth Croce, Bioperspective.com. 

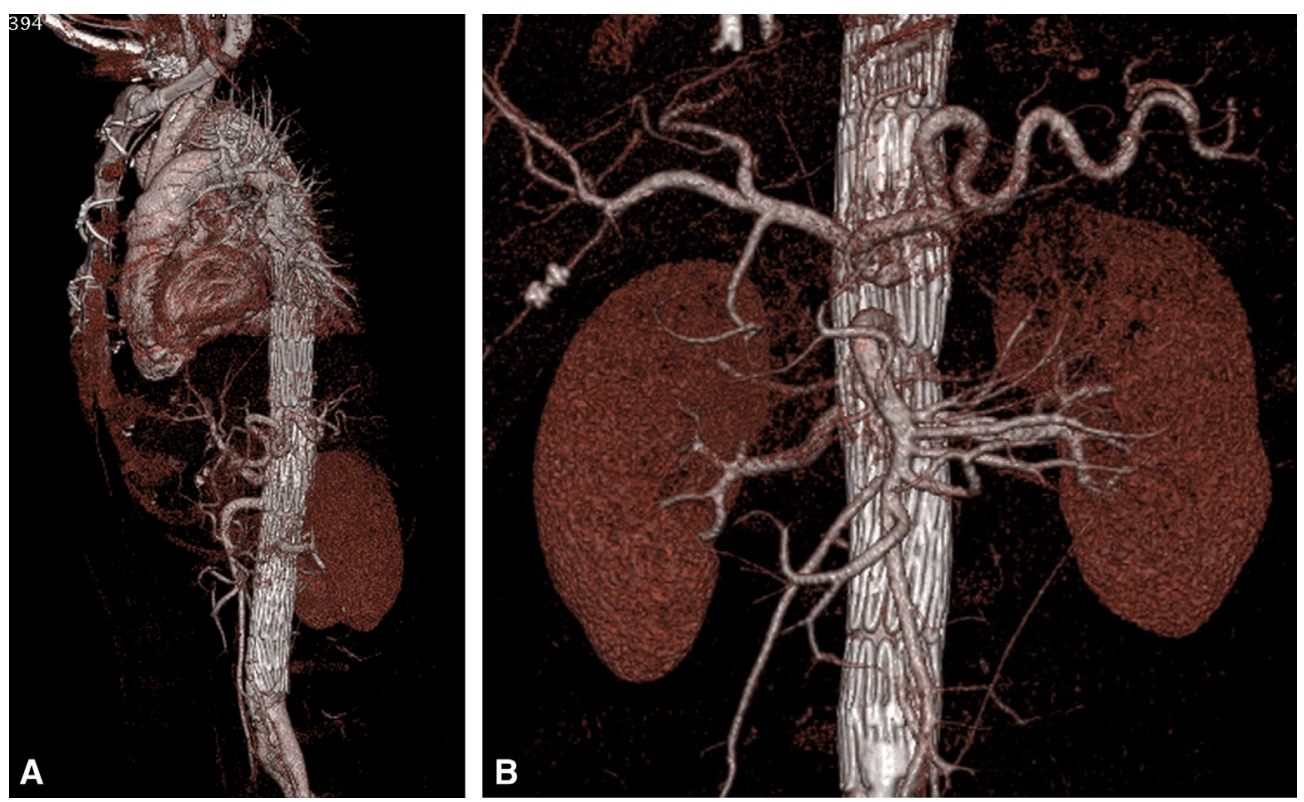

FIGURE 7. A, Computed tomography (CT) aortogram at 4 years post total aortic repair for acute type A aortic dissection with 3-dimensional reconstruction demonstrating a stable aorta with no false lumen patency. B, CT aortogram of visceral branches including left renal artery stent.

the false sac in the proximal descending aorta. Eight patients have demonstrated complete FL thrombosis (Figure 7). The other 7 patients had short segments of FL flow in the bare metal stented portions of the descending aorta or abdominal aorta. This is most likely related to incomplete rupture of the septum and failure to achieve reapposition of the layers of the aorta. Incomplete fenestration was more likely in the chronic setting where the septum can be quite tough. We were unable to achieve complete fenestration of the septum with balloon rupture in all 3 of these patients. These areas of FL flow are freely communicating with the TL through fenestrations in the septum above and below and thus are not pressurized. Thus far on serial imaging, they have remained stable and none have required intervention for aneurysmal dilatation. Two of these patients had further covered stents to exclude FL flow at the junction between covered and bare metal stent portions at 10 months and 32 months respectively. These patients had reintervention, as it was relatively simple to exclude these areas. Longer-term follow-up is required to determine whether these areas of FL flow may lead to complications in the future. One patient had coiling to the left subclavian artery that had not been debranched at the initial surgical repair. All 3 of these reinterventions were successful.

\section{CONCLUSIONS}

Replacement of the ascending aorta and hemi arch with an open distal anastomosis has long been the standard in the management of ATAAD. It is seen as simple and reproducible and the most likely to yield a live patient, especially in inexperienced hands. However, this conservative approach may expose the patient to the acute complications of mal-perfusion and to a more complex and riskier situation in the medium to long term. In our experience, a more complete approach to ATAAD using our new paradigm of total aortic repair can minimize the acute hazards and reduce the need for future interventions. The branch-first arch replacement technique allows safe and controlled replacement of the arch and provides a long Dacron landing zone for subsequent thoracoabdominal stenting. By treating the whole dissected aorta, we aim to obliterate the FL and ensure true lumen flow, preventing the acute complications of branch vessel mal-perfusion while also reducing the incidence of late aneurysmal formation. Larger numbers and longer follow-up are required before this technique could be routinely recommended in patients presenting with ATAAD.

\section{Webcast}

You can watch a Webcast of this AATS meeting presentation by going to: https://aats.blob.core.windows.net/media/ 18AO/26-br-1645-matalanis-v2.mp4.

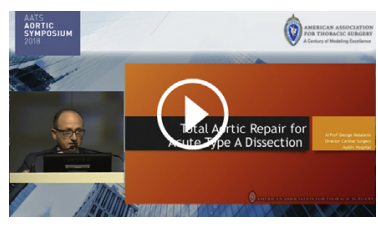




\section{Conflict of Interest Statement}

Authors have nothing to disclose with regard to commercial support.

\section{References}

1. Berretta P, Patel HJ, Gleason TG, Sundt TM, Myrmel T, Desai N, et al. IRAD experience on surgical type A acute dissection patients: results and predictors of mortality. Ann Cardiothorac Surg. 2016;5:346-51.

2. Augoustides JG, Szeto WY, Desai ND, Pochettino A, Cheung AT, Savino JS, et al. Classification of acute type A dissection: focus on clinical presentation and extent. Eur J Cardiothorac Surg. 2011;39:519-22.

3. Olsson C, Hillebrant CG, Liska J, Lockowandt U, Eriksson P, FrancoCereceda A. Mortality in acute type A aortic dissection: validation of the Penn classification. Ann Thorac Surg. 2011;92:1376-82.

4. Geirsson A, Bavaria JE, Swarr D, Keane MG, Woo YJ, Szeto WY, et al. Fate of the residual distal and proximal aorta after acute type a dissection repair using a contemporary surgical reconstruction algorithm. Ann Thorac Surg. 2007;84: 1955-64; discussion 1955-64.

5. Halstead JC, Meier M, Etz C, Spielvogel D, Bodian C, Wurm M, et al. The fate of the distal aorta after repair of acute type A aortic dissection. J Thorac Cardiovasc Surg. 2007;133:127-35.

6. Kimura N, Tanaka M, Kawahito K, Yamaguchi A, Ino T, Adachi H. Influence of patent false lumen on long-term outcome after surgery for acute type A aortic dissection. J Thorac Cardiovasc Surg. 2008;136:1160-6. 1166.e1-3.

7. Tsagakis K, Tossios P, Kamler M, Benedik J, Natour D, Eggebrecht H, et al. The DeBakey classification exactly reflects late outcome and re-intervention probability in acute aortic dissection with a slightly modified type II definition. Eur J Cardiothorac Surg. 2011;40:1078-84.

8. Fattouch K, Sampognaro R, Navarra E, Caruso M, Pisano C, Coppola G, et al. Long-term results after repair of type a acute aortic dissection according to false lumen patency. Ann Thorac Surg. 2009;88:1244-50.

9. Bajona P, Quintan E, Schaff HV, Daly RC, Dearani JA, Greason KL, et al. Aortic arch surgery after previous type A dissection repair: results up to 5 years. Interact Cardiovasc Thorac Surg. 2015;21:81-5; discussion 85-6.

10. Spear R, Hertault A, Van Calster K, Settembre N, Delloye M, Azzaoui R, et al. Complex endovascular repair of postdissection arch and thoracoabdominal aneurysms. J Vasc Surg. 2018;67:685-93.

11. Berguer R, Parodi JC, Schlicht M, Khanafer K. Experimental and clinical evidence supporting septectomy in the primary treatment of acute type B thoracic aortic dissection. Ann Vasc Surg. 2015;29:167-73.
12. Tsai MT, Wu HY, Roan JN, Tsai YS, Hsieh PC, Yang YJ, et al. Effect of false lumen partial thrombosis on repaired acute type A aortic dissection. $J$ Thorac Cardiovasc Surg. 2014;148:2140-6.e3.

13. Alimohammadi M, Sherwood JM, Karimpour M, Agu O, Balabani S, Diaz-Zuccarini V. Aortic dissection simulation models for clinical support: fluid-structure interaction vs. rigid wall models. Biomed Eng Online. 2015 $14: 34$.

14. Poon SS, Theologou T, Harrington D, Kuduvalli M, Oo A, Field M. Hemiarch versus total aortic arch replacement in acute type A dissection: a systematic review and meta-analysis. Ann Cardiothorac Surg. 2016;5:156-73.

15. Iafrancesco M, Goebel N, Mascaro J, Franke UFW, Pacini D, Di Bartolomeo R, et al. Aortic diameter remodelling after the frozen elephant trunk technique in aortic dissection: results from an international multicentre registry. Eur J Cardiothorac Surg. 2017;52:310-8.

16. Leontyev S, Tsagakis K, Pacini D, Di Bartolomeo R, Mohr FW, Weiss G, et al. Impact of clinical factors and surgical techniques on early outcome of patients treated with frozen elephant trunk technique by using EVITA open stent-graft: results of a multicentre study. Eur J Cardiothorac Surg. 2016;49:660-6.

17. Williams DM, Brothers TE, Messina LM. Relief of mesenteric ischemia in type III aortic dissection with percutaneous fenestration of the aortic septum. Radiology. 1990;174:450-2.

18. Trimarchi S, Segreti S, Grassi V, Lomazzi C, Cova M, Piffaretti G, et al. Open fenestration for complicated acute aortic B dissection. Ann Cardiothorac Surg. 2014:3:418-22.

19. Watkinson AF. A novel "cheese wire" technique for stent positioning following difficult iliac artery subintimal dissection and aortic re-entry. Cardiovasc Intervent Radiol. 2009;32:781-4.

20. Hofferberth SC, Nixon IK, Boston RC, McLachlan CS, Mossop PJ. Stent-assisted balloon-induced intimal disruption and relamination in aortic dissection repair: the STABILISE concept. J Thorac Cardiovasc Surg. 2014;147: 1240-5.

21. Nienaber CA, Kische S, Zeller T, Rehders TC, Schneider H, Lorenzen B, et al Provisional extension to induce complete attachment after stent-graft placement in type B aortic dissection: the PETTICOAT concept. J Endovasc Ther. 2006;3: $738-46$.

22. Matalanis G, Galvin SD, Wu HY, Roan JN, Tsai YS, Hsieh PC, Yang YJ "Branch-first" continuous perfusion aortic arch replacement and its role in intra-operative cerebral protection. Ann Cardiothorac Surg. 2013;2:194-201.

Key Words: aortic dissection, aortic repair, aortic arch repair, branch first, abdominal stenting, endovascular repair 